\title{
Study on Preparation of cementitious capillary crystalline waterproofing coating
}

\author{
Guozhong LU, Weixuan ZHAO and Dewei DAI
}

\author{
Beijing Building Materials Academy of Sciences Research, Beijing 100041।
}

\begin{abstract}
Keywords: cementitious; capillary; crystalline; waterproof coating; infiltration resistance.
Abstract. The cement and quartz sand were the main substrate which mixed with a variety of active chemicals was prepared in capillary crystalline waterproof coating. And the influence were explored that the varieties and the amount of cement, quartz sand gradation and actives impact on the cementitious capillary crystalline waterproofing coating performance. The test shows all performance indexes have reached and exceeded 18445-2001 standard, which also is not lower than foreign products of this kind.
\end{abstract}

\section{Introduction}

Waterproofing materials can be divided into two categories, flexible waterproof materials and rigid waterproof materials. Practice at home and abroad has proved that traditional flexible waterproof materials such as coil and coating have the features of flexibility and good durability, but they are poor at adhesion, and out of use in the case of wet base surface or seepage, and are not suitable for dorsal surface and wet surface. Rigid cementitious waterproofing material is widely used because of the superior performance that flexible waterproof materials don't have. But most rigid cementitious waterproof materials are the substances of surface sealing waterproofing agent, and the effect of waterproof only works on the surface. It cannot penetrate into the internal structure automatically and deeply so that it doesn't have a permanent waterproofing effect. As time passed by, it degenerated continuously. Once the waterproof layer has been destroyed, the waterproof ability also disappeared and easily led to alkali-aggregate reaction. From this analysis of concrete cracking reason, project application features, and waterproof feature, it is necessary to develop permanent cementitious capillary crystalline waterproofing material with the features of micro fractures self-healing, crystalline, and dorsal surface construction. The development and application of new waterproofing materials such as cementitious capillary crystalline waterproofing coating is necessary.

Cementitious capillary crystalline waterproofing coating is a kind of powdery material based on cement and quartz sand, incorporated into a variety of active chemical substance. The active chemical substance of this kind of coating is carried by water or osmosis, which transports in the micro porous and capillary of the concrete, fills the particles and the incompletely hydrated components. It can form insoluble branches and tendrils of crystal, combined with the concrete as a whole to make up the micro fracture by hydrating once again. It can be used for positive side waterproofing and dorsal surface waterproofing, and more suitable for wet substrate surface construction.

The research purpose of cementitious capillary crystalline waterproofing coating is to substitute imported products, reduce costs, and promote technological development of our new waterproof materials. The paper explore the content of cement types, cement amount and quartz sand grading of cementitious capillary crystalline waterproofing coating, and investigate the performance impact of active substance on cementitious capillary crystalline waterproofing coating.

\section{Materials and Testing Methods}

Materials and equipment. 425 Portland cement, 70-140mesh quartz sand, sodium, methylation of sodium condensate, silicone materials, calcium hydroxide, cellulose ethers; mineral admixture is silica fume; dispersible powder is latex powder; admixtures are super plasticizer and early strength agent; machine include cement paste machine, cement mortar triple tryout of $40 \mathrm{~mm} \times 40 \mathrm{~mm} \times 160 \mathrm{~mm}$, 8 font, penetration testing machine which all come from WuXi XiYi Instrument Building Materials. 
Pieces preparation and performance test. The coating is mixed directly by ratio. The method of performance test is according to national standard GB18445-2001.

\section{Results and Discussion}

The impact of cement types and amount on strength, alkali content and construction. Cementitious capillary crystalline waterproofing coating is a kind of powdery material based on cement and quartz sand, incorporated into a variety of active chemical substance. So the variety of cement has a great influence on strength and construction of coating. The relationship is shown in figure1.

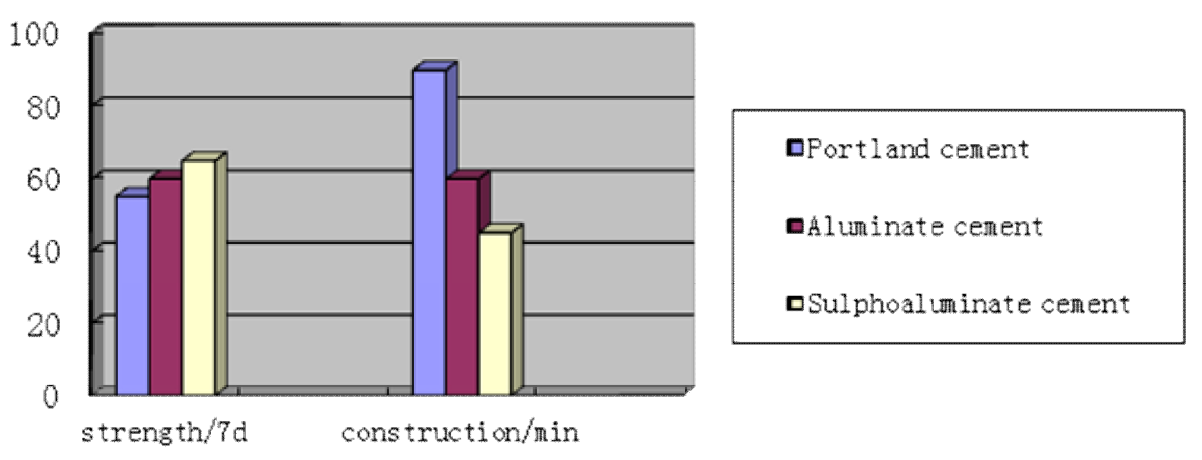

Figure 1 The relationship of cement type and strength, construction

Form figure1, considering the factor of strength and construction performance, Portland cement is suitable for such coating. The construction technology of the coating is brushing which need both better strength and certain operation time. The amount of cement has an impact on coating strength and alkali content, the relationship is shown in figure2. Alkali in coating is main brought by cement, aggregate, and admixtures. So the total alkalinity of product should be controlled strictly to avoid the damage of concrete caused by ARR, and improve the durability of buildings and structures.

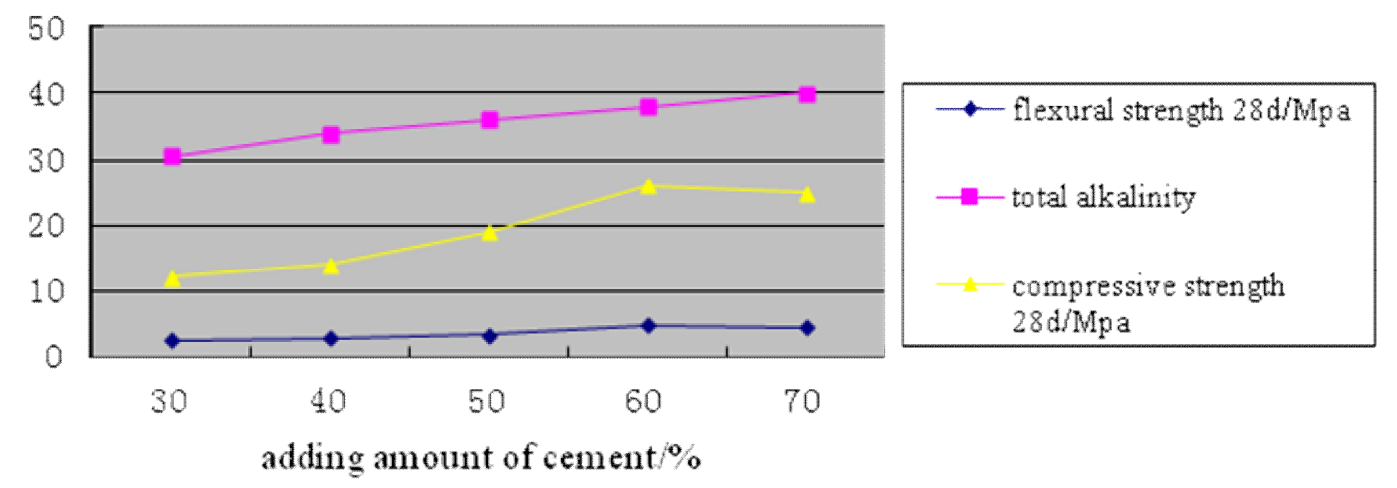

Fiture 2 The relationship of cement amount and strength, alkali content

Seen from figure2, the strength of coating reduces after the first increase with the increase of the cement amount. The test results show that the amount of cement in coating is generally about $60 \%$.

The impact of quartz sand grading on homogeneity and crack resistance of coating. Quartz sand grading means proportion of different particle sizes of quartz sand. Because the gap among sand particle is filled with grout, the gap should be reduced to save cement and improve strength. If there is only one particle size, the porosity is the largest; if there are two different particle sizes, the porosity will reduce. For reducing the gap, different particle size sand will be selected to achieve good particle size distribution. Sieving is the method of testing sand particle size distribution to determine qualified 
degree of graded sand. In accordance with national construction code requirements, the coating thickness is $0.8-1.0 \mathrm{~mm}$. The smaller particle size quartz sand should be selected to ensure homogeneity and crack resistance of coating in the case of meeting grading. Test results show that 40percent is the best add amount of quartz sand. Especially the relationship of fineness and amount of graded sand is when fineness is 40-70 mesh, the amount is 20percent; when fineness is 70-100 mesh, the amount is 35percent; when fineness is 200 meshes, the amount is 45 percent. The relationship of fineness and amount is shown in figure 3.

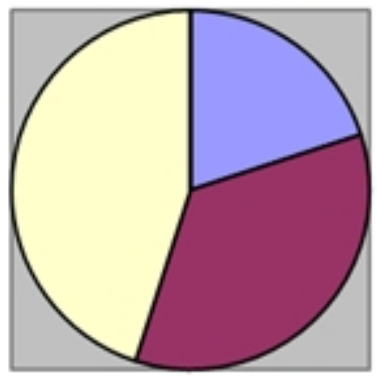

$$
\begin{aligned}
& \mathbf{\square}_{40-70 \text { mesh }} \\
& \mathbf{\square}_{70-100 \text { mesh }} \\
& \mathbf{\square}_{200 \text { mesh }}
\end{aligned}
$$

Figure 3 Guartz sand grading

Impact of active compounds on the second impermeability pressure of coating. Impermeability pressure can be divided into positive side impermeability pressure and dorsal surface impermeability pressure. Positive side impermeability pressure should be tested for outer waterproof and dorsal surface impermeability pressure should be tested for inner waterproof. Cementitious capillary crystalline waterproofing coating can be used as both inner waterproof material and outer waterproof material. Test results show that there are certain relevance between positive side impermeability pressure and dorsal surface impermeability pressure. To reflect material properties, impermeability is tested on dorsal surface by standards, and the second impermeability pressure is used to reflect material self-healing which is used to distinguish other waterproof materials. The core substance of self-healing is active compound. The relationship of active compound and impermeability pressure is shown in figure 4 .

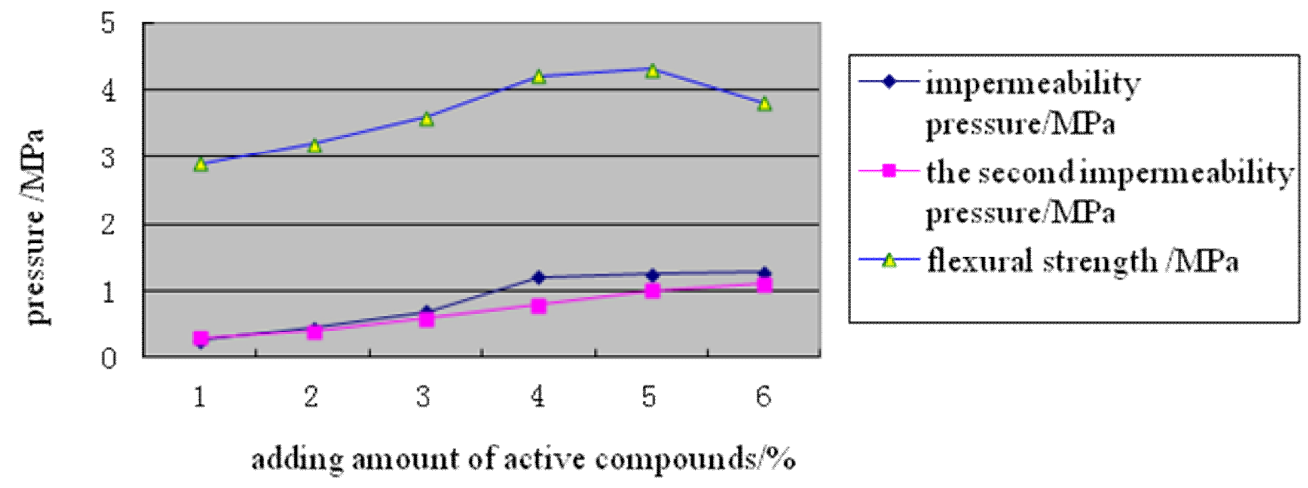

Figure 4 The relationship of active and impermeability pressure

From figure4, the impermeability pressure and the second impermeability pressure increase with the increase of active compound, and the flexural strength decrease after fist increase. The reason is caused by the increase of needle-like crystals formed by the active substance in cementitious capillary crystalline waterproofing coating, and the decrease of colloidal crystallization formed by calcium in catalytic cement. Test results show that the best performance to price ratio of coating is achieved when the adding amount of active substance is 4 percent to 5 percent.

Impact of infiltration reduction active substances and hydrophobic active substance on coating impermeability pressure. Generally, there are many methods to improve water-tightness of concrete and mortar. One of the methods is filling early pore with hydration gel which is generated by adding infiltration reduction substances to promote hydration. The other methods are filling pore of 
concrete with fine materials to cut off seepage channel and mixing hydrophobic substance or hydrophobic component generated with cement ingredients. The use of infiltration reduction active substances as one kind of inorganic compounds is achieving the purpose of impermeability by the method of reducing porosity and improving the density of material. Infiltration reduction active substances or compound formed by reaction between infiltration reduction active substance and hydration products can fill up the capillary channel in concrete, and reduce the porosity. Hydrophobic active substance with the feature of hydrophobic treatment is organic compounds, which can change capillary from hydrophilic to hydrophobic. It can turn concrete surface into hydrophobic surface, which can reduce seepage caused by capillary action, and improve water resistance of concrete. Most of hydrophobic active substances are silicone or siloxane-based material. The adding amount of reduced permeability active substance and hydrophobic active substance is 1percent to 3percent of the amount of cement, and the relationship with coating impermeability pressure is shown in figure 5 .

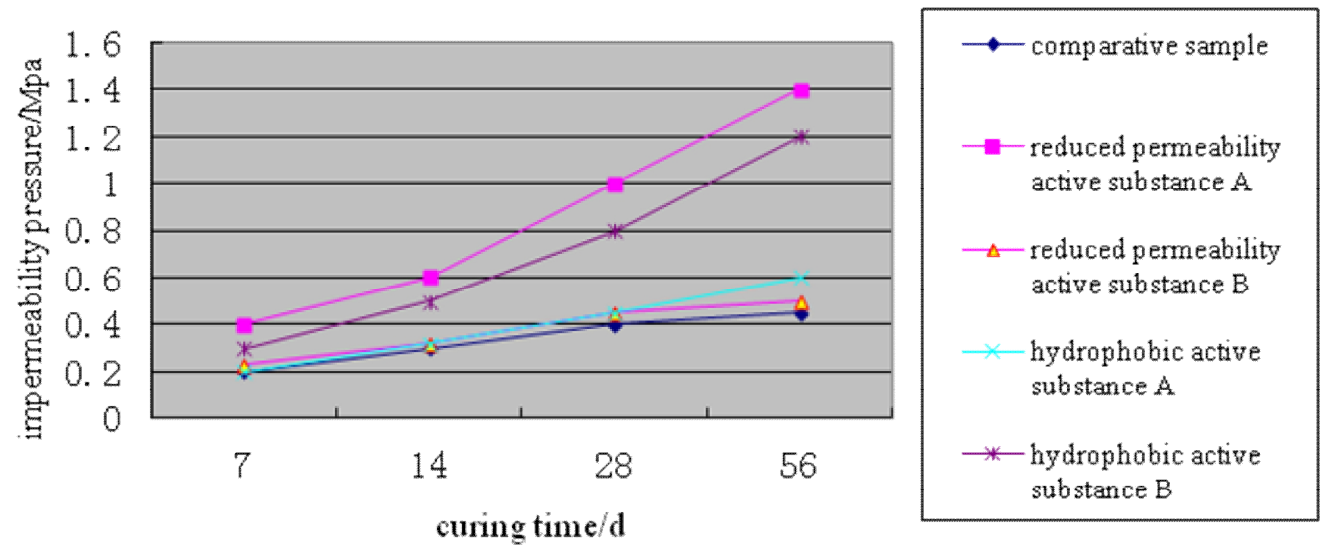

Figure 5 The relationship of coating impermeability pressure and reduced permeability substance, hydrophobic substance

As seen in figure5, reduced permeability active substance and hydrophobic active substance can increase impermeability pressure. Results show that reduced permeability active substance A and hydrophobic active substance B have the better results for increasing the impermeability pressure. Reduced permeability active substance A is siliceous powder, can fill the gap because of the fineness. On the other hand, it can react with cement to promote early hardening, and prevent dissolution of water-soluble substances, which resulting in the increase of impermeability with the increasing of strength. Hydrophobic active substance B is silane additives, in the high alkaline environment, hydrophilic organic functional silane group is hydrolyzed to form the highly reactive silanol groups. It continues react with hydroxyl groups in cement hydration products, and fixes at the surface of concrete pore wall. Hydrophobic organic functional groups toward the outside of pore wall, which leads to the hydrophobic of pore surface, improves wet adhesion of coating, and forms the performance of waterproof and breathable.

Impact of sodium silicate modulus on impermeability and anti-alkaline of coating. Generally, calcium ion(Ca2+) and silicon ion(SiO32-) necessary for cement crystallization in concrete will decrease over time, which inhibit the behavior of hydration and formation of crystalline. Sodium can add silicate ion which is necessary for cement crystallization, and combine with calcium hydroxide generated by the hydration reaction to generate insoluble calcium silicate crystals. Through this series of process, the impermeability of concrete is improved. Sodium silicate, also known as water glass, is composed of different ratios of sodium oxide and silicon dioxide, the molar ratio of silicon dioxide and sodium oxide is called modulus. The relationship of sodium silicate basic properties and modulus is shown in figure6. 


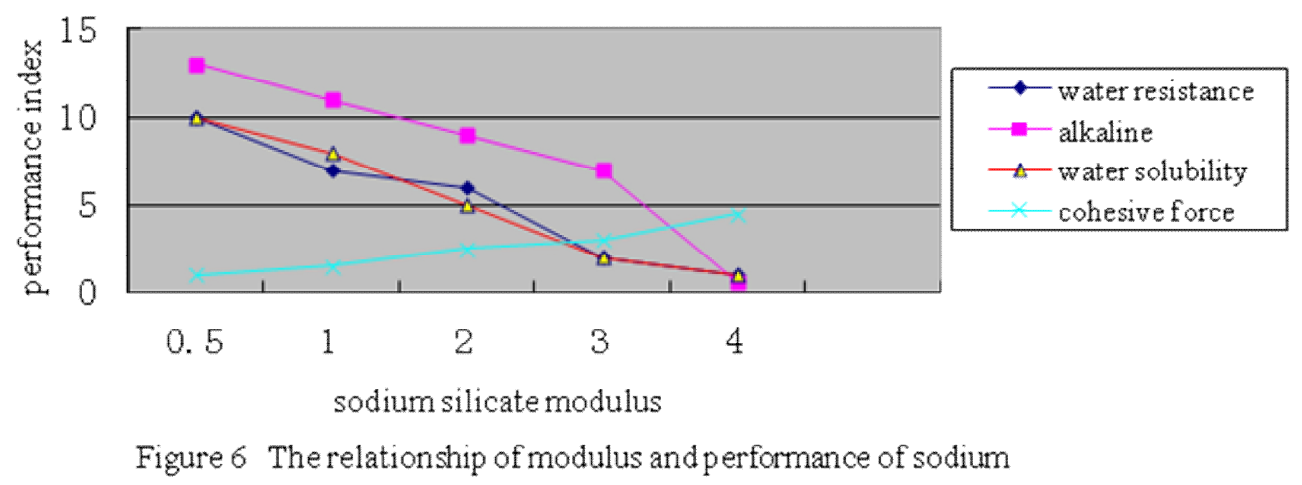

As seen in figure6, the property of sodium varies with different proportions of silicon dioxide and sodium oxide, and the degree of difficulty of dissolution is determined by the modulus. When $\mathrm{n}$ is less than or equal to 1, sodium silicate can be dissolved in water under room temperature; when $n$ is more than 1 , sodium silicate can only be dissolved in hot water; when $\mathrm{n}$ is more than 3 , sodium silicate can only be dissolved in the steam $405.3 \mathrm{k}$. The modulus is lower, the adhesion is worse, and water resistance of coating after filming is better. The modulus is higher, the adhesion is greater, and the water resistance of coating after filming is worse. When $n$ is more than 3 , sodium is neutral, and when $\mathrm{n}$ is less than3, sodium is alkaline. According to the impact of sodium on solubility, adhesion strength and alkaline, the good modulus is 1 when preparation coating use water glass. But when the modulus is 1 , the alkaline is strong, which easily back to base to coating. So the right adding amount of mineral admixtures and dispersible powder is necessary to inhibit anti-alkaline of coating.

Inhibition of mineral admixtures and dispersible powder to phenomenon of anti-alkaline for coating. Silica fume is one kind of active mineral admixtures with the main component of amorphous silica, which is collected by oxide silicon vapor excluded from the flue when smelting industrial silicon or silicon alloy. It has the characteristic of hardening in water, and can improve the performance of compactness, frost resistance, and fluidity. Dispersible powder is powdery polymer made by the method of spray drying. Test prove that there are synergy between silica fume and latex powder which can inhibit anti-alkaline of coating and improve early water resistance strength. The mechanism of synergy is the physical and chemistry between surfactant in latex powder and mineral admixtures. First, surfactant adsorbed on the surface of ultrafine mineral powder, which enhance the potential and play a better role of water less, dispersion, plasticized, filling and homogenization. Second, the adding of ultrafine mineral powder can fill the gap and defect of internal structure of cement slurry, reduce the amount of latex powder used to fill the gap and defect, and make latex powder wrapped in silica fume and cement particle surface to inhibit the forming and expand of crack. The compound efficacy is improved through the combined effect of the above points, and the phenomenon of anti-alkaline is inhibited, the performance of early water resistant is improved. Tests prove that the adding amount of 1.5 percent silica fume and 0.5 percent latex powder is best.

The relationship of admixtures and coating construction. The species of admixtures used in cementitious capillary crystalline are superpasticizer and early strength agent. Superplasticizer is one kind of admixtures which can meet the specified requirements of consistency under the premise of reducing the unit water, and improving the coating workability. It has strong dispersion to cement. Through the action of polar adsorption, it can reduce the attractiveness among cement particles, damage and hinder flocculation between particles to release the water in floc, and improve the workability ultimately. The relationship of admixture content and fluidity is shown in figure 7. 


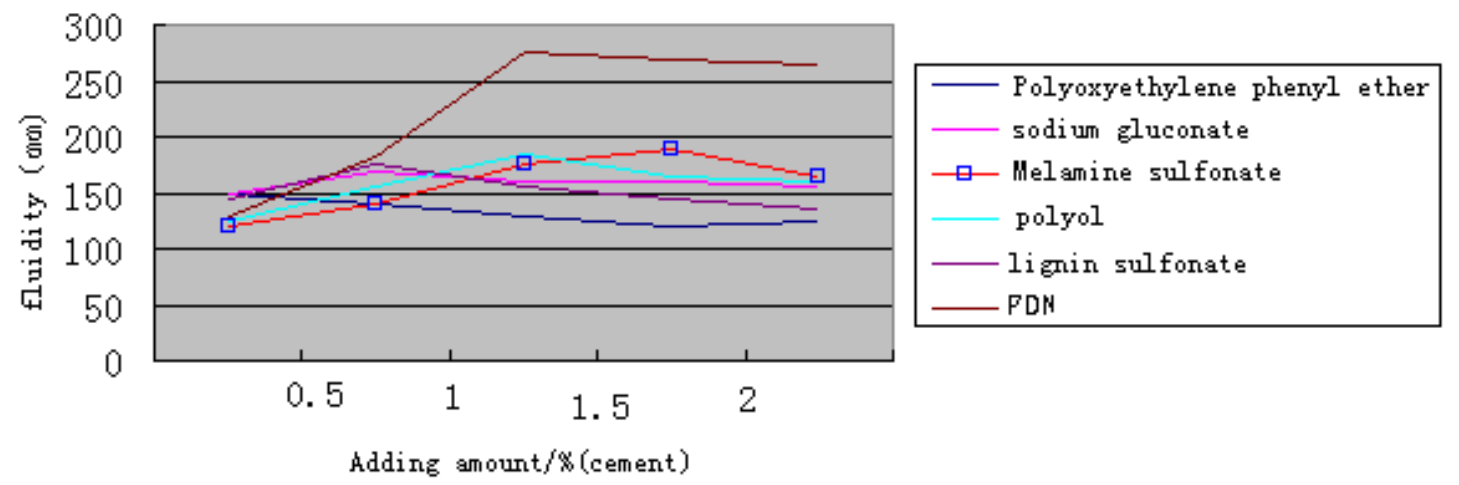

Figure 7 The relationship of admixture and coating fluidity

As seen in figure7, the effect of FDN is the best, which adding amount is 1-1.5percent of the amount of cement. Early strength agent is one kind of admixtures which can improve early strength of concrete and have no significant effect on late strength. The combine use of early strength agent and supeuplasticizer both ensure the role of less water, enhancement, and compacting; also play the advantage of early strength. Tests prove that A calcium is selected as early strength agent, and the adding amount is 0.5 percent of the amount of cement.

\section{Conclusions}

(1) The type and adding amount of cement has a great influence on cementitious capillary crystalline. High strength is achieved by adding Portland cement of amount of 60percent.

(2) Coating crack resistance and strength can be significantly increased by reasonable grading of quartz sand. The best relationship of fineness and amount is when fineness is 40-70 mesh, the amount is 20percent; when fineness is 70-100 mesh, the amount is 35percent; when fineness is 200 mesh, the amount is 45 percent.

(3) Impermeability pressure and strength of coating are affected by active material; it is higher when the adding mount of active material is about 4percent.

(4) Impermeability and respiratory of coating can be improved by the adding of reduced infiltration and hydrophobic active substances. The synergy of admixture and dispersible powder can inhibit the alkaline overflow of sodium, and improve the performance of anti-reversion alkaline.

(5) Coatings prepared have good advantages of self-healing and environmental protection, which indicators have reached or exceeded the standards of GB18445-2001.It is a kind of good performance cementitious capillary crystalline waterproofing coating.

\section{References}

[1] Peijie Zhou, Qinghua Gu. Performance Study on Cementitious Capillary Crystalline Waterproofing Coating[J]. New Building Materials, 2002, (4):43-45.

[2] Jianying Yu, Guiming Wang. Research of YJH Capillary Crystalline Waterproofing Materials[J]. China Building Waterproof Industry, 2004,(9):13-17.

[3] Bing Chen, Zhengwu Jiang, Hua Bai. Performance Research of Cementitious Capillary Crystalline Waterproofing Materials[J]. New Building Materials, 2000, (12):10-11.

[4] Shaozu Xue. The Analysis and Development of Foreign Cementitious Capillary Crystalline Waterproofing Materials[J]. China Building Waterproofing Industry, 2001,(6):14-17. 